\title{
PENENTUAN STRATIGRAFI KECEPATAN GELOMBANG GESER (VS) DI DAERAH RAWAN ABRASI KABUPATEN BENGKULU UTARA MENGGUNAKAN METODE MULTICHANNEL ANALYSIS OF SURFACE WAVE (MASW)
}

\author{
Refrizon $^{1^{*},}$, Nanang Sugianto ${ }^{2}$, dan Admo Bernard ${ }^{2}$ \\ ${ }^{1}$ Fisika, Fakultas MIPA, Universitas Bengkulu, Bengkulu \\ ${ }^{2}$ Lembaga Penelitian dan Pengabdian pada Masyarakat UNIB, Bengkulu \\ *email: refrizon@unib.ac.id
}

\begin{abstract}
ABSTRAK
Struktur batuan bawah permukaan yang lemah diduga salah satu faktor penyebab tingginya laju abrasi di Kabupaten Bengkulu Utara. Struktur batuan bawah permukaan ini diestimasi berdasarkan analisis nilai kecepatan gelombang geser (Vs) dari pengukuran Multichannel Analysis of Surface Wave (MASW) di 20 titik sepanjang garis pantai. Nilai Vs diinterpretasikan berupa profil $1 D$ dan 2D untuk menggambarkan struktur dan jenis material penyusun batuan di tiap kedalaman dan lapisan. Hasil analisis menunjukkan bahwa stratigrafi nilai Vs bawah permukaan di daerah rawan abrasi Bengkulu Utara terdiri tiga lapis batuan. Lapisan pertama dengan nilai $V s<180 \mathrm{~m} / \mathrm{s}$ yang mengindikasikan didominasi oleh lempung lunak, lapisan kedua $180<V s<360 \mathrm{~m} / \mathrm{s}$ didominasi oleh tanah kaku dan lapisan ketiga $360<V s<760 \mathrm{~m} / \mathrm{s}$ mengindikasikan didominasi oleh tanah yang sangat padat dan batuan lunak. Material penyusun batuan terdiri dari endapan pasir, kerikil, lempung, dan alluvium yang tingkat kepadatannya rendah dan bervariasi tiap-tiap kedalaman. Tidak ditemukan adanya indikasi batuan keras hingga kedalaman 30 meter, hanya batuan berstruktur lunak yang sangat mudah retak dan rapuh. Hasil ini menunjukkan bahwa struktur batuan bawah permukaan di daerah rawan abrasi Bengkulu Utara ini merupakan batuan berstruktur lemah yang rentan mengalami deformasi seperti crack, settlement, dan collapse seperti fenomena abrasi yang selama ini terjadi.
\end{abstract}

Kata kunci: stratigrafi, gelombang geser, MASW, abrasi.

\begin{abstract}
Weak subsurface rock structures are thought to be one of the factors causing high abrasion rates in North Bengkulu Regency. This subsurface rock structure is estimated based on the analysis of shear wave velocity (Vs) from the measurement of Multichannel Analysis of Surface Wave (MASW) at 20 points along the coastline. Vs values are interpreted in the form of $1 D$ and $2 D$ profiles to illustrate the structure and type of constituent material in each depth and layer. The results of the analysis show that the stratigraphy of the subsurface Vs value in abrasion-prone areas of North Bengkulu consists of three layers of rock. The first layer with a value of $V s<180 \mathrm{~m} / \mathrm{s}$ indicated to be dominated by soft clay, the second layer $180<V s<360 \mathrm{~m} / \mathrm{s}$ was dominated by rigid soil and the third layer $360<V s<760 \mathrm{~m} / \mathrm{s}$ indicated dominated by very dense soil and soft rock. Composition of rocks consists of deposits of sand, gravel, clay, and alluvium which have a low density and vary in each depth. There were no indications of hard rock to a depth of 30 meters, only soft-structured rocks that were very easily cracked and brittle. These results indicate that the subsurface rock structure in the abrasion-prone areas of North Bengkulu is a weak structural rock that is susceptible to deformation such as crack, settlement, and collapse like the abrasion phenomenon that has occurred so far.
\end{abstract}

Keywords: stratigraphy, shear wave, MASW, abrasion.

\section{PENDAHULUAN}

Kabupaten Bengkulu Utara merupakan kabupaten yang masuk ke dalam kategori kabupaten yang rawan bencana abrasi pantai (coastal erosion) tertinggi di Provinsi
Bengkulu dan bahkan menjadi urutan ke-70 kabupaten yang rawan terhadap bencana gelombang ekstrim dan abrasi pantai di Indonesia (BNPB, 2013). Kecepatan abrasi beberapa daerah di Bengkulu sebagaimana 
dilaporkan oleh Suwarsono dkk (2011) mencapai 2,5 meter/tahun. Berdasarkan data foto udara, Bengkulu Utara mengalami perubahan garis pantai mencapai 25 meter/tahun (Samdara dan Lubis, 2016). Farid dkk (2014) melaporkan bahwa coastal erosion rates di Kabupaten Bengkulu Utara adalah $1,1 \mathrm{~m} /$ tahun hingga $5,8 \mathrm{~m} /$ tahun. Sempadan pantai merupakan bagian dari daratan tepi pesisir pantai yang mengalami erosi. Sempadan pantai adalah kawasan tertentu sepanjang pantai yang lebarnya sesuai dengan bentuk dan kondisi fisik pantai serta minimal $100 \mathrm{~m}$ dari titik pasang tertinggi ke arah daratan (Triadmodjo, 1999) seperti yang terlihat pada Gambar 1. Sempadan pantai di Bengkulu menjadi salah satu sumber daya wilayah pesisir yang memiliki banyak manfaat bagi masyarakat seperti untuk pelabuhan, transportasi, agribisnis, kawasan industri, pariwisata, perikanan, budi daya, serta menjadi kawasan pemukiman warga sehingga perlu dipertahankan kelestariannya. Namun, karena adanya fenomena abrasi, kawasan sempadan pantai di Kabupaten Bengkulu Utara telah terancam kemanfaatannya bagi masyarakat yang ada di sekitar.

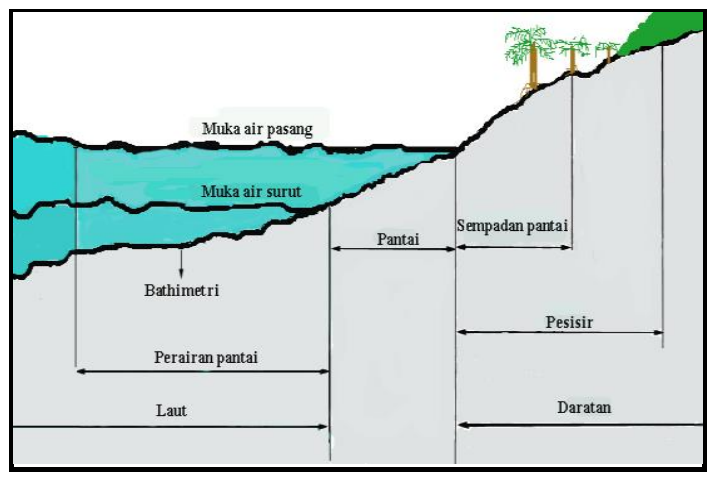

Gambar 1. Definisi dan batasan pantai (Triadmodjo, 1999).

Kondisi geologi lokal di sempadan pantai dapat menjadi faktor pengontrol besaran laju erosi, terutama dalam menghambat atau mempercepat terjadinya denundasi pantai atau serangkaian proses panjang yang mengakibatkan pengikisan batuan di permukaan. Kondisi geologi yang lunak dan rapuh adalah sebagian dari ciri-ciri kondisi geologi yang mudah mengalami deformasi, demikian juga halnya dengan terjadinya longsoran dan abrasi. Kabupaten Bengkulu Utara dapat dikelompokkan ke dalam delapan jenis pantai. Menurut Farid dkk (2013), saat ini empat diantara delapan jenis pantai tersebut telah mengalami erosi yaitu; (1) stone tufa rugged coast sand, (2) stone clay rugged coast tufa, (3) rugged coast alluvial clay, dan (4) cliff rugged beach. Hasil ini didasarkan pada analisis respon seismik seperti dominant frequency, amplification factor, Peak ground acceleration, Seismic vulnerability index, Ground Shear Strain dan Attenuation factor (Farid dkk, 2013, Farid dkk, 2014, dan Farid dkk 2016). Selain itu, berdasarkan analisis potensi likuifaksi dan respon seismik, likuifaksi di dearah rawan abrasi Kabupaten Bengkulu Utara dimungkinkan akan terjadi pada kedalamann 0 hingga 7,5 meter yang didominasi oleh low soil resistance seperti sandy soils (Mase, 2017 dan Mase, 2018). Semua hasil di atas menyebutkan bahwa daerah rawan abrasi di Bengkulu Utara memiliki struktur batuan bawah permukaan yang lemah dan memiliki gaya kohesif yang rendah sehingga mudah mengalami deformasi ketika ada gangguan dari luar.

Meskipun secara garis besar telah dibahas bagaimana struktur batuan dan bagaimana potensi likufaksi di daerah rawan abrasi di Kabupaten Bengkulu Utara, namun sifat dan struktur batuan sampai pada kedalaman tertentu (stratigrafi) belum dibahas. Sifat dan struktur dari stratigrafi batuan tersebut dapat diketahui berdasarkan interpretasi pengukuran metode geofisika, salah satunya adalah metode seismik aktif yaitu dengan metode Multichannel Analysis of Surface Wave $(M A S W)$. Interpretasi MASW tersebut adalah berupa profil shear wave velocity $(V s)$ tiap kedalaman dan tiap perlapisan batuan. Pada penelitian ini digunakan metode MASW untuk mendapatkan nilai shear wave velocity $(V s)$. Metode ini telah diuji dalam berbagai penelitian untuk menentukan stratigrafi daerah survey dimana metode ini dianggap cukup efektif dalam menggambarkan stratigrafi batuan bawah permukaan secara detail. Pemodelan perlapisan batuan yang diperoleh dalam menghasilkan stratigrafi dapat mencapai nilai minimum misfit yang kecil. Berdasarkan nilai $V s$, dapat diestimasi karakteristik tiap lapisan batuan sekaligus mengestimasi jenis material penyusun batuan. 
Metode MASW merupakan metode yang memanfaatkan fenomena disperse gelombang permukaan yang bertujuan untuk mengevaluasi karakter suatu medium solid. Secara umum metode $M A S W$ mengukur variasi kecepatan gelombang permukaan seiring dengan bertambahnya kedalaman. Metode $M A S W$ diperkenalkan oleh Park dkk (1998), yang berkaitan dengan keheterogenan medium tanah di bawah permukaan yang kemungkinan bervariasi secara lateral. Panjang gelombang berhubungan dengan kedalaman, panjang gelombang akan berkurang seiring bertambahnya kedalaman. Penelitian ini menerapkan pengukuran $M A S W$ dengan sumber seismik aktif untuk menghasilkan gelombang permukaan dengan 24 rangkaian geofon. Geofon menerima dan mengukur hasil rekaman yang ditimbulkan pada beberapa jarak dari sumber getaran. Tiap geofon mengandung banyak gelombang permukaan, masing-masing dengan panjang gelombang yang berbeda-beda. Skema pengukuran dan luaran data metode $M A S W$ ditunjukkan seperti Gambar 2. luaran hasil pengolahan data diinterpretasikan berupa profil kecepatan gelombang geser 1-D yang diperoleh dari hasil inversi kurva dispersi menggunakan metode alogaritma genetik, dimana dasarnya dilakukan untuk mendapatkan model yang paling baik (mendekati sebenarnya) dengan missfit minimum.

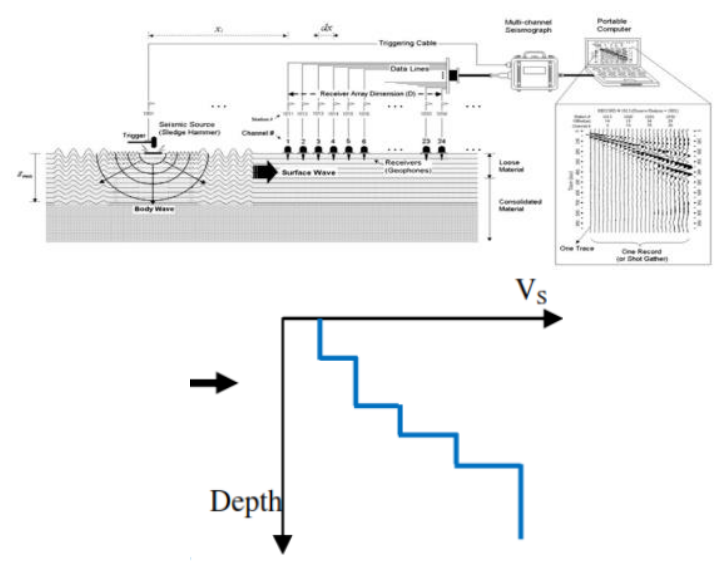

Gambar 2. Skema survei lapangan $M A S W$ aktif (atas). Ilustrasi profil kecepatan gelombang geser 1-D (Park dkk, 1998).

Besaran nilai Shear wave velocity atau kecepatan gelombang geser pada suatu tempat berhubungan dengan jenis material penyusun batuan yang dilewatinya. Bagitu pula bahwa besar kecilnya nilai kecepatan gelombang geser dipengaruhi oleh tingkat kelunakan dan kekerasaan lapisan batuan. Fokus pada analisis hasil dari interpretasi stratigrafi kecepatan gelombang geser ( $V s$ ) pada penelitian ini adalah jenis material penyusun atau deskripsi statigrafi batuan yang didasarkan pada tabel hubungan

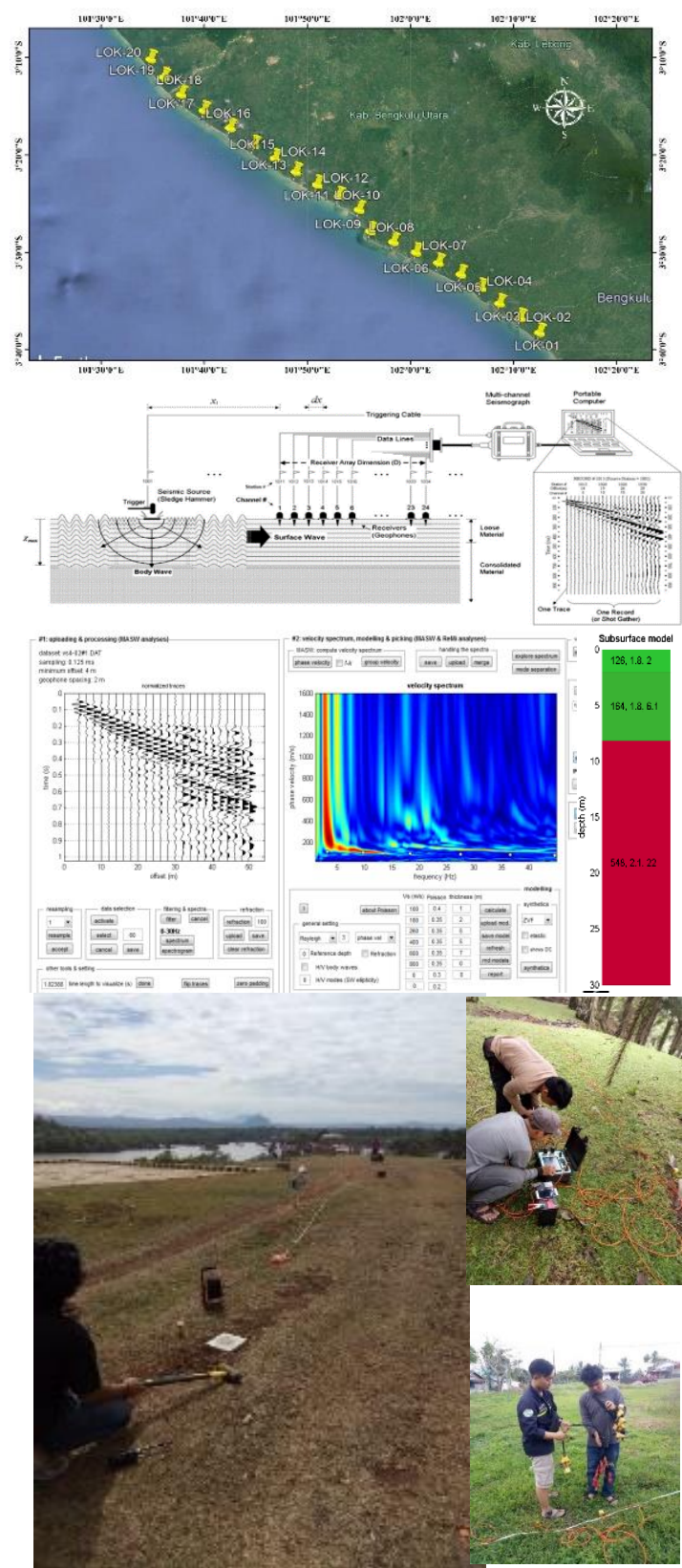

kecepatan gelombang geser untuk berbagai jenis material (CEN, 2004 dan SISTEN, 2005) dan tabel deskripsi sifat (lunak/keras) lapisan batuan (NEHRP, 1998 dan Motazedian dkk, 2010). 
Gambar 3. Skema pengukuran dan pengolahan data MASW. Mulai dari atas ke bawah: distribusi titik pengukuran di sempadan pantai Kabupaten Bengkulu Utara, teknik pengukuran dengan 24 geofon (Park dkk, 1998), ilustrasi pengolahan data menggunakan WINMASW dan model stratigrafi 1D output dari WINMASW yang berisi nilai $V s$, densitas $(\rho)$ dan ketebalannya, serta dokumentasi akuisisi data.

\section{DATA DAN METODE}

Pengukuran respon seismik dengan metode $M A S W$ pada penelitian ini dilakukan di dua puluh titik pengukuran MASW yang didistribusikan sepanjang sempadan pantai kabupaten Bengkulu Utara. Jarak antar titik pengukuran lebih kurang $4 \mathrm{~km}$. Respon seismik direkam menggunakan digital portable seismometer type $16 \mathrm{~S} 24 \quad 24$ Channels dengan $5 \mathrm{kali}$ pengulangan pengukuran. Semua data diolah menggunakan perangkat lunak WINMASW untuk memperoleh model 1D nilai shear wave velocity terhadap kedalaman. Model yang dipilih adalah model terbaik yang memiliki nilai root mean square (rms) terkecil. Model 1D ini diekstrak yang kemudian datanya digunakan untuk menghasilkan profil 2D hasil interpolasi nilai shear wave velocity semua data menggunakan Surfer. Skema teknik pengukuran dan metode pengolahan data $M A S W$ ditunjukkan seperti Gambar 3.

\section{HASIL DAN PEMBAHASAN}

Nilai shear wave velocity (Vs) di sepanjang sempadan pantai Kabupaten Bengkulu diinterpretasikan ke dalam 2 model, yaitu model stratigrafi 1D dan model stratigrafi penampang 2D (hasil interpolasi model stratigrafi 1D). Model ini diinterpretasikan hingga kedalaman 30 meter dari permukaan. Nilai $V s$ dikelompokkan berdasarkan tabel site classification oleh NEHRP (NEHRP, 1998), Motazedian (Motazedian, 2010), CEN (CEN, 2004), dan SISTEN (SISTEN, 2005), yang mendiskripsikan tingkat kekerasan dan jenis material penyusun batuan. Setiap kelompok nilai $V s$ diberi warna kontur yang berbeda untuk membedakan satu dengan yang lainnya. Interpretasi ini memberikan kemudahan dalam memahami statigrafi nilai $V s$ bawah permukaan di daerah rawan abrasi Kabupaten Bengkulu Utara. Berdasarkan nilai $V s$, daerah rawan abrasi Kabupaten Bengkulu Utara tergolong pada tiga kelompok warna yaitu kontur biru muda dengan nilai $V s<180 \mathrm{~m} / \mathrm{s}$, warna hijau dengan nilai $180<V s<360 \mathrm{~m} / \mathrm{s}$, dan warna kuning dengan nilai $360<V s<760 \mathrm{~m} / \mathrm{s}$. Model stratigrafi 1D dan 2D nilai shear wave velocity di Kabupaten Bengkulu Utara ditunjukkan pada Gambar 4.

Gambar 4 paling atas adalah peta sebaran dua puluh titik pengukuran MASW di sempadan pantai Kabupaten Bengkulu Utara. Jarak titik pengukuran dari bibir pantai berkisar antara 5 sampai 25 meter (tergantung medan) menjauhi pantai ke arah daratan. Model stratigafi 1D hasil pengolahan dari 20 data $M A S W$ ditunjukkan pada Gambar 4 yang dibawah sesudahnya.
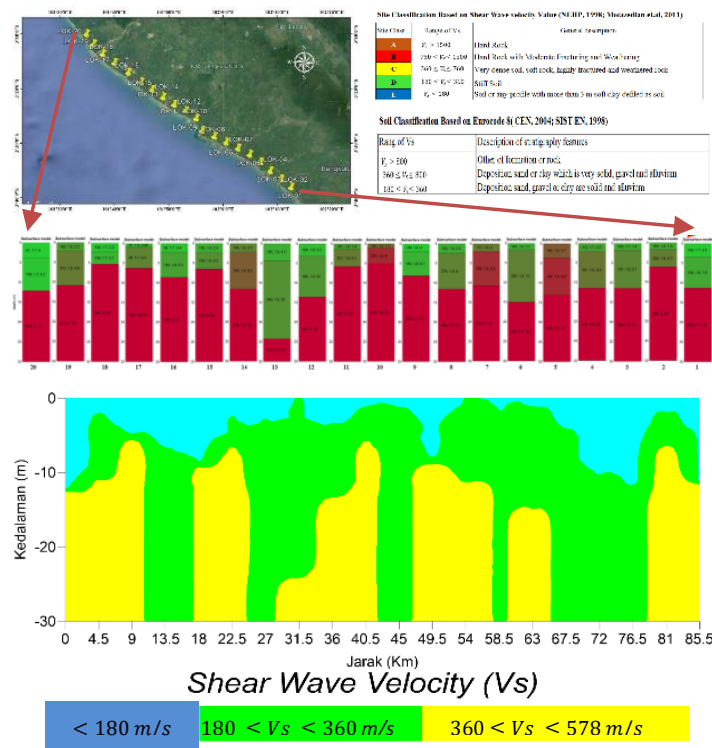

Gambar 4. Mulai dari atas peta sebaran titik pengukuran $M A S W$ yang dibawahnya model statigrafi 1D secara berurut dari sebelah Utara ke Selatan dan lebih di bawah model stratigrafi 2D shear wave velocity di sepanjang sempadan pantai daerah rawan abrasi Kabupaten Bengkulu Utara.

Ada tiga nilai yang diinformasikan di dalam tiap batang model 1D pada Gambar 4b. Nilai tersebut secara berturut-turut terdiri dari ketebalan lapisan, nilai shear wave velocity $(V s)$ dan nilai densitas batuan $(\rho)$. Model 1D dari software WINMASW hanya memberikan informasi mengenai nilai $V s$ dan densitas yang diinterpretasikan sampai pada kedalaman 30 meter dari permukaan. Interpretasi yang dihasilkan ini selanjutnya dapat dikelompokkan berdasarkan tabel site classification, untuk itu model stratigrafi 1D 
diekstrak dan diinterpolasikan menjadi model stratigrafi 2D seperti yang ditunjukkan pada Gambar 4 dibawahnya.

Kelompok nilai $V s$ di bawah $180 \mathrm{~m} / \mathrm{s}$, kontur diberi warna biru. Kontur biru teridentifikasi pada lapisan pertama pada batuan bawah permukaan di sepanjang sempadan pantai Bengkulu Utara. Warna kontur ini mencapai ketebalan yang berbeda-beda untuk masingmasing titik. Lapisan batuan dengan warna kontur biru diperkirakan berupa tanah atau batuan lunak yang secara umum merupakan lempung lunak (soft clay) sebagai penyusun tanah. Endapan tanah diperkirakan berkohesi yang rendah hingga sedang sehingga secara umum merupakan lapisan tanah lunak. Selain lempung lunak lapisan penyusun batuan dengan kontur ini juga dapat terdiri dari alluvium pada permukaan yang ketebalannya bervariasi antara 5 hingga 20 meter. Stratigrafi dengan nilai $V s$ dibawah $180 \mathrm{~m} / \mathrm{s}$ secara fisis adalah batuan lunak terhampar di permukaan sehingga bila dikenai oleh gelombang air laut (ombak laut) sangat rentan mengalami berbagai jenis deformasi seperti crack, settlement, dan collapse. Hal inilah yang menjelaskan mengapa pantai Bengkulu Utara mudah mengalami abrasi, yaitu ombak laut yang menghempas di pantai bertemu langsung dengan batuan lunak $(V s<180 \mathrm{~m} / \mathrm{s})$.

Kelompok warna kontur berikutnya adalah hijau. Kontur hijau menggambarkan batuan lapisan kedua di bawah permukaan sempadan pantai Kabupaten Bengkulu Utara. Berdasarkan nilai $V s$ lapisan kedua diperkirakan adalah batuan berstruktur kaku atau stiff soil. Batuan ini secara visual di sepanjang pantai Bengkulu Utara terlihat lebih padat dibandingkan dengan lapisan pertama. Berbeda dengan batuan lapisan pertama, jenis material penyusun batuan lapisan kedua tidak hanya soft clay, melainkan juga terdiri dari endapan pasir, gravel, dan alluvium. Struktur lapisan batuan dengan kontur hijau lebih kuat dan solid dibandingkan dengan lapisan pertama. Hasil yang sama diperoleh pada lapisan batuan ketiga (kontur kuning). Lapisan batuan ketiga juga tersusun atas endapan pasir, gravel, clay dan alluvium. Hanya saja pada lapisan ketiga struktur endapannya lebih padat dibandingkan dengan batuan lapisan kedua.
Lapisan batuan berkontur kuning ini bisa mencapai ketebalan beberapa puluh meter dan ditandai dengan peningkatan sifat mekanik yang bertahap terhadap kedalaman. Karakteristik batuan lapisan ketiga secara umumnya merupakan very dense soil, soft rock dan highly fractured weathered rock, artinya batuan dengan kontur kuning merupakan lapisan batuan yang lunak dengan potensi perekahan yang masih tinggi.

Berdasarkan survei MASW, tidak ditemukan adanya indikasi batuan keras di sepanjang sempadan pantai Kabupaten Bengkulu Utara hingga kedalaman 30 meter di bawah permukaan. Ketiga lapisan batuan merupakan batuan yang berstrtuktur lunak dan sangat rentan terhadap deformasi. Secara geologis diketahui bahwa struktur batuan bawah permukaan daerah sempadan pantai kabupaten Bengkulu Utara memiliki struktur batuan bawah permukaan yang cenderung tidak stabil. Hasil ini memiliki hubungan yang linear jika dikaitkan dengan laju abrasi yang terjadi di Kabupaten Bengkulu Utara. laju abrasi tentunya akan tergantung pada energi hempasan gelombang laut dan kondisi kemiringan sempadan pantai.

\section{KESIMPULAN}

Nilai shear wave velocity (Vs) di daerah rawan abrasi Kabupaten Bengkulu berdasarkan survei $M A S W$ terbagi menjadi tiga kelompok nilai yaitu $V s<180 \mathrm{~m} / \mathrm{s}$, $180<V s<360 \mathrm{~m} / \mathrm{s}$, dan $360<V s<760 \mathrm{~m} / \mathrm{s}$. Masing-masing kelompok nilai ini memberikan gambaran yang berbeda mengenai struktur dan jenis material penyusun batuan. Lapisan batuan yang memiliki nilai $V s<180 \mathrm{~m} / \mathrm{s}$ diperkirakan adalah tanah atau profil lain yang umumnya merupakan lempung lunak (soft clay) sebagai penyusun batuan. lapisan bauan yang miliki nilai $V s \quad 180-360 \mathrm{~m} / \mathrm{s}$ diperkirakan batuan yang berstruktur kaku atau stiff soil dan lapisan batuan yang miliki nilai Vs 360-760 $\mathrm{m} / \mathrm{s}$ merupakan very dense soil, soft rock dan highly fractured weathered rock. Ketiga jenis lapisan batuan ini adalah batuan yang berstrutktur lunak dan diperkirakan tersusun atas beberapa jenis material yaitu endapan pasir, gravel, clay dan alluvium yang tingkat kepadatannya bervariasi tiap lapisan. Tidak ditemukan adanya indikasi batuan keras hingga kedalaman 30 meter. Ketiga lapisan 
batuan ini merupakan lapisan batuan lunak yang sangat rentan mengalami berbagai jenis deformasi seperti crack, settlement, dan collapse layaknya fenomena abrasi.

\section{UCAPAN TERIMA KASIH}

Terimakasih disampaikan kepada Skim Penelitian PNBP FMIPA Universitas Bengkulu tahun 2018 dan group peneliti Bidang Kebumian Program Studi Fisika dan Program Studi Geofisika, Jurusan Fisika FMIPA Universitas Bengkulu.

\section{DAFTAR PUSTAKA}

BNPB., 2013, Indeks Resiko Bencana Indonesia (IRBI) 2013, Badan Nasional Penanggulangan Bencana, Jakarta.

CEN., 2004, Eurocode 8-design of Structures for Earthquake Resistance. Part 1: general rules, seismic actions and rules for buildings. European Standard EN 1998-1, Desember 2004, European Committee for Standardization, Brussles.

Farid, M., and Suryanto, W., 2016, Microseismic Wave Measurements to Detect Landslides in Bengkulu Shore with Attenuation Coefficient and Shear Strain Indicator, $K n E$ Engineering, 2016, 7, DOI: 10.18502/2016/keg.v1i1.477.

Farid, M., Brotopuspito, S, K., Wahyudi., Sunarto., Suryanto, W., 2014, Ground Shear Strain and Rate of Erosion in The Coastal Area of North Bengkulu, Indonesia. Advanced Materials Research, 896, 521-524, Trans Tech Publications, Switzerland. doi: 10.4028/www.scientific.net/AMR.89 6.521

Farid, M., Brotopuspito, S, K., Wahyudi., Sunarto., Suryanto, W., 2013, The Relationships Among Ground Shear Strain, Shore Characteristics And Abrasion On The West Coast Of Bengkulu Province, Indonesia, Caspian Journal of Applied Sciences Research, 2(AICCE'12 \& GIZ' 12), 424-430, ISSN: 2251-9114, CJASR.
Mase, L. Z. 2018. Seismic Response Analysis Along the Coastal Area of Bengkulu During the September 2007 Earthquake. Makara Journal Technology. 22/1 (2018), 37-45

Mase, L. Z., 2017, Liquefaction Potential Analysis Along Coastal Area of Bengkulu Province due to the 2007 Mw 8.6 Bengkulu Earthquake, $J$. Eng. Technol. Sci, ITB Journal Publisher, 49, 6, 2017, 721-736, ISSN: 2337-5779

Motazedian, D., Hunter, J.A., Pugin, A., Crow, H., 2010, Development Of A Vs30(NEHRP) Map For The City Of Ottawa, Ontario, Canada. NRS Research Press, Canada.

National Earthquake Hazard Reduction Program (NEHRP), 1998, Recommended Provisions for Seismic Regulation for New Buildings and other Structures 1997 edition. Technical Report, FEMA 302, Federation Emergency Management Agency, Washington.

Park, C. B., Miller, R. D., and Xia, J., 1998, Multi-channel analysis of surface waves using Vibroseis (MASW): 66th Ann. Internat, Mtg., Soc. Expl. Geophys., Expanded Abstracts, 6871.

Samdara, R., and Lubis, A.M., 2016, Shoreline Changes At Northern Coast Of Bengkulu Using PALSAR and Optic Data During 2007-2011, Journal international Engneering and Sciences.

SISTEN 1998-1:2005/oA101, 2005, Eurocode 8-design of Structures for Earthquake Resistance, Part 1: general rules, seismic actions and rules for buildings, National Annex, Slovenian Institute for Standardrization, Ljubljana.

Suwarsono, Supiyati dan Suwardi., 2011, Zonasi Karakteristik Kecepatan Abrasi Dan Rancangan Teknik Penanganan Jalan Lintas Barat Bengkulu Bagian Utara Sebagai Jalur Transportasi Vital, Makara Teknologi: 15, 1, 31-38. Triadmodjo, B., 1999, Teknik Pantai, Beta Offset, Yogyakarta. 